\title{
Comparison of regional and global reanalysis near-surface winds with station observations over Germany
}

\author{
A. K. Kaiser-Weiss ${ }^{1}$, F. Kaspar ${ }^{1}$, V. Heene ${ }^{1}$, M. Borsche ${ }^{1}$, D. G. H. Tan ${ }^{2}$, P. Poli ${ }^{2}$, A. Obregon ${ }^{1}$, and \\ H. Gregow ${ }^{3}$ \\ ${ }^{1}$ Deutscher Wetterdienst, Frankfurter Straße 135, 63067 Offenbach, Germany \\ ${ }^{2}$ European Centre for Medium-Range Weather Forecasts, Shinfield Park, Reading, RG2 9AX, UK \\ ${ }^{3}$ Finnish Meteorological Institute, P.O. Box 503, 00101 Helsinki, Finland
}

Correspondence to: A. K. Kaiser-Weiss (andrea.kaiser-weiss@dwd.de)

Received: 24 January 2015 - Revised: 9 May 2015 - Accepted: 1 July 2015 - Published: 29 July 2015

\begin{abstract}
Reanalysis near-surface wind fields from multiple reanalyses are potentially an important information source for wind energy applications. Inter-comparing reanalyses via employing independent observations can help to guide users to useful spatio-temporal scales. Here we compare the statistical properties of wind speeds observed at 210 traditional meteorological stations over Germany with the reanalyses' near-surface fields, confining the analysis to the recent years (2007 to 2010). In this period, the station time series in Germany can be expected to be mostly homogeneous. We compare with a regional reanalysis (COSMO-REA6) and two global reanalyses, ERA-Interim and ERA-20C. We show that for the majority of the stations, the Weibull parameters of the daily mean wind speed frequency distribution match remarkably well with the ones derived from the reanalysis fields. High correlations (larger than 0.9) can be found between stations and reanalysis monthly mean wind speeds all over Germany. Generally, the correlation between the higher resolved COSMO-REA6 wind fields and station observations is highest, for both assimilated and non-assimilated (i.e., independent) observations. As expected from the lower spatial resolution and reduced amount of data assimilated into ERA-20C, the correlation of monthly means decreases somewhat relative to the other reanalyses (in our investigated period of 2007 to 2010). Still, the inter-annual variability connected to the North Atlantic Oscillation (NAO) found in the reanalysis surface wind anomalies is in accordance with the anomalies recorded by the stations.

We discuss some typical examples where differences are found, e.g., where the mean wind distributions differ (probably related to either height or model topography differences) and where the correlations break down (because of unresolved local topography) which applies to a minority of stations. We also identified stations with homogeneity problems in the reported station values, demonstrating how reanalyses can be applied to support quality control for the observed station data.

Finally, as a demonstration of concept, we discuss how comparing feedback files of the different reanalyses can guide users to useful scales of variability.
\end{abstract}




\section{Introduction}

Atmospheric reanalysis is "a consistent reprocessing of archived weather observations using a modern forecasting system" (Dee et al., 2014). The past two decades have brought forth remarkable advances in the quality and quantity of the resulting reanalysis datasets (Dee et al., 2014; Bosilovich et al., 2013; Hartmann et al., 2013). These advances have been accompanied (and in many respects catalysed) by rapid growth in uptake of reanalysis datasets for a diverse and growing range of applications. But it remains challenging for individual users to know which (if any) of the available datasets (whether from reanalysis or other procedures) are appropriate for their applications (see, e.g., Gregow et al., 2015). Assessing "fitness-forpurpose" requires synthesising knowledge about (a) the relative strengths/limitations of the available datasets, (b) the extent to which such characteristics affect the fidelity of derived results, and (c) the user's own application-specific tolerance of uncertainty; it is important to note that fitness for one purpose does not guarantee fitness for all purposes. Here, we describe the inter-comparisons that were undertaken to elucidate the relative properties of the near-surface winds over Germany in two global and one regional reanalysis datasets on the time scale of days to several years. The inter-comparisons employ independent wind observations from German weather stations and also illustrate how reanalyses can support quality control of the observations. The COSMO-REA6 regional reanalysis is driven by the global ERA-Interim reanalysis, and covers Europe with increased spatial and temporal resolution. We demonstrate that intercomparison of reanalyses can help to guide users to useful scales of variability.

For the purpose of wind energy production, for example, there are dedicated wind mast measurements, which measure at a certain point over a short period of time and at heights typical for wind energy production. This is highly valuable for wind energy applications, but it remains desirable to add to this short-term information an estimate of the inter-annual temporal variability, as is typically available in the time series of station measurements made for traditional weather/climate applications (approximately $10 \mathrm{~m}$ above ground). In Germany, these are relatively abundant and evenly distributed and cover many decades. On the other hand, observation practices, instruments, and the height of the sensor above ground might have changed over time. This information should ideally be found in the metadata accompanying the historical station records. It is also valuable to track changes in the surroundings (like growing trees or changes in land cover) and measurement or processing errors, but this is not uniformly available worldwide given historical variations in the rigour of observing practice around the globe.

Reanalyses also provide wind information, here derived from a physically consistent state of the atmosphere using a state-of-the-art NWP model, constrained by the whole observing system. While larger wind energy companies might be able to build their own wind measurement masts and develop sophisticated analyses, other users like smaller enterprises, district managers, government agencies, or interested individual citizens rely on products based on station measurements at $10 \mathrm{~m}$ above ground, and statistical models build upon those, like e.g., wind climatologies at levels of interest for wind energy production (Gerth and Christoffer, 1994). All these users might draw benefit from our study.

Reanalysis wind fields have been found to differ from station records on the multi-decadal scale. The so-called "stilling effect", i.e., a decrease of wind speeds deduced from station measurements since the 1970s, is reported in many papers on mid-latitude wind observations (see McVicar et al., 2012, for a comprehensive review). This is in general contrast to various reanalyses, which do not show a stilling effect (Smits et al., 2005; McVicar et al., 2008, 2012, and references therein). Several reasons have been suggested. Longterm changes in surface roughness could explain, at least partly, the difference (Vautard et al., 2010; Wever, 2012). Changes in aerosols, sea surface temperature and greenhouse gas concentrations were found to be unlikely causes (Bichet et al., 2012). There still remain the possibilities that measurement artefacts, or processes not modelled in the reanalysis, may contribute to the discrepancies.

In this work we do not investigate the multi-decadal stilling effect directly, but report on a preparatory multi-annual study. We focus on the area of Germany and the period 2007 to 2010. Although the dataset is short, it is best fitted for the inter-comparison since all stations are known to operate automatically, instrumental problems are unlikely, and changes in surface roughness are negligible. This allows us to characterize the recent variability captured in regional and global reanalysis near surface wind fields, and to compare their statistical characteristics with the traditional station measurements. Several approaches have been identified as useful for reanalysis comparisons (see Fig. 1) and applied below for the near-surface wind fields, namely direct comparisons (Sect. 3.1 and 3.2), thematic comparisons (Sect. 3.3) and internal metrics comparisons (Sect. 3.4).

\section{Data}

We used the $10 \mathrm{~m}$ wind fields and feedback files containing the radiosonde data from the global reanalysis ERA-Interim (Dee et al., 2011). The data of this reanalysis are available from the ECMWF website http://apps.ecmwf.int/datasets/. ERA-Interim is based on the ECMWF Integrated Forecast System, IFS (Cy31r2), 4-dimensional variational analysis (4D-Var) with a 12-h analysis window, and assimilation of a wide range of surface and upper-air observational data from both in-situ and satellite instruments. The spatial resolution of the data set is approximately $80 \mathrm{~km}$ (T255 spectral) on 60 


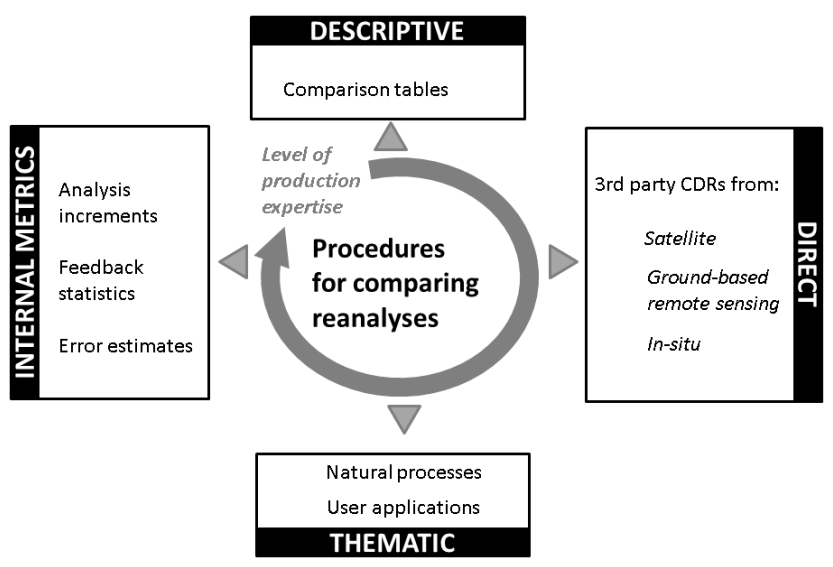

Figure 1. Useful approaches for intercomparing reanalyses include: (1) descriptive, e.g., a comparison table of characteristics, (2) direct comparisons with in-situ, ground-based remote sensing or satellite observations, (3) thematic comparison, and (4) internal metrics comparison.

vertical levels from the surface up to $0.1 \mathrm{hPa}$. For comparison with station data, the interpolated fields (interpolated to $0.125^{\circ}$ ) as obtained from the ECMWF website are taken.

We also used the ERA-20C reanalysis (Poli et al., 2013; Dee et al., 2014), also accessed through http://apps.ecmwf. int/datasets/. This reanalysis provides a global realization at spectral resolution T159 which corresponds to the horizontal resolution of the reduced Gaussian grid of $\sim 125 \mathrm{~km}$. The data assimilation method applied is an updated version of the 4D-Var scheme (IFS Cy38r1) and used a 24-h assimilation window but it assimilated observations of surface pressure and surface marine winds only. From ERA-20C, the $10 \mathrm{~m}$ winds as pre-processed by ECMWF and interpolated to $0.125^{\circ}$ horizontal resolution were taken for this comparison study.

The third reanalysis product used is the COSMO-based regional reanalysis of DWD's Hans-Ertel Centre for Weather Research (HErZ), University of Bonn (Bollmeyer et al., 2014, http://www.herz-tb4.uni-bonn.de/) called COSMOREA6. The regional reanalysis COSMO-REA6 is driven via the global reanalysis boundary conditions (ERA-Interim) every $3 \mathrm{~h}$. It is based on the COSMO-model and applies nudging as the data assimilation technique. Here we use data from a configuration that was run for the European CORDEX domain at a nominal resolution of $0.055^{\circ}$. From COSMOREA6, the wind speed at the ground layer $(10 \mathrm{~m})$ as well as feedback files containing radiosonde data were used in the work below.

The station data and associated metadata were taken from the freely accessible climate data archive of Deutscher Wetterdienst (DWD) which is available through ftp://ftp-cdc. dwd.de/pub/CDC/observations_germany/climate/ (Kaspar et al., 2013). Available are the station data and associated metadata describing the particularities of the station instrumen- tation and measurement time series. From this archive (August 2014, version v002), the example station observations below were chosen. The station observations of wind speeds are not assimilated within ERA-Interim and ERA-20C, i.e., are independent measurements. For COSMO-REA6, station data below $100 \mathrm{~m}$ are assimilated, above $100 \mathrm{~m}$ they are not, i.e., the former may be dependent, the latter are independent measurements.

The North Atlantic Oscillation (NAO) index was taken from http://www.cru.uea.ac.uk/ timo/datapages/naoi. $\mathrm{htm}$ which is an extension of Jones et al. (1997).

For our comparison, we took the grid cells matching the location of the station from the regional reanalysis, and from the global reanalyses interpolated by $0.125^{\circ}$ (provided by ECMWF). Because it cannot be expected that processes on the sub-daily scale can be resolved in the archived global reanalysis datasets, we compare frequency distributions of daily means. The correlation coefficients were calculated with monthly means, which were calculated from daily means, to avoid the issue of calculating correlations with incomplete time series. Here we restrict ourselves to the time period 2007 to 2010, which is the overlap period of COSMOREA6 at our disposal. In this time span, we are relatively confident no large changes in surroundings of the stations occurred, the method of measurements remained constant, and no gross errors are expected. As users would especially be interested in information about the past spanning many decades, we include ERA-20C into our preparatory comparisons because of its length. ERA-Interim is used as a benchmark. Based on the comparison, we discuss the potential of reanalyses to enhance the traditional approaches for assessing wind variability based on the $10 \mathrm{~m}$ station winds.

\section{Results}

For an illustration of spatial variability, the $10 \mathrm{~m}$ surface winds from the regional reanalysis COSMO-REA6 and the interpolated global reanalysis ERA-20C for February 2007 are shown in Fig. 2. The higher wind speeds over the North and Baltic Seas are prominent in both reanalyses as well as the sharp decline at the coast line. As expected, due to the much finer horizontal resolution of the COSMO-REA6 regional reanalysis, higher spatial variability is present here. Note the coincidences of wind features with topographical features, e.g., mountain ridges in the South of East Germany (compare to Fig. 3). The features related to topography are more pronounced in the regional reanalysis, e.g., the landsea transition and the wind speed variability over the heterogeneous low mountain ranges in Mid-Germany. Note, however, the close match of the average absolute values of both reanalysis datasets. 

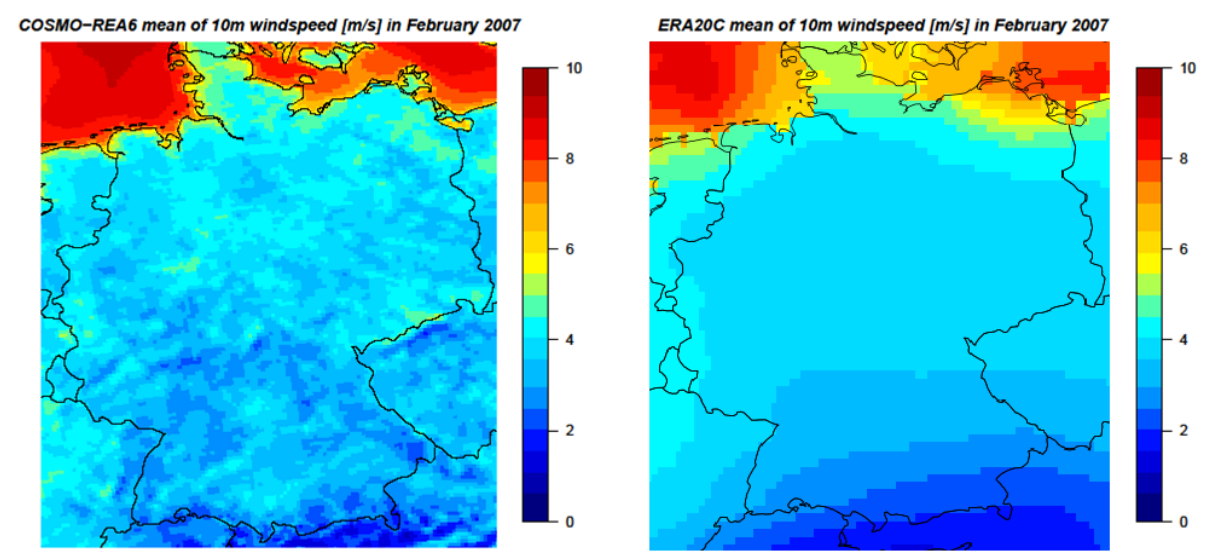

Figure 2. $10 \mathrm{~m}$ surface winds from the COSMO-REA6 regional reanalysis (left) and the ERA-20C interpolated wind fields (right) illustrate the different spatial resolution for the month of February 2007.

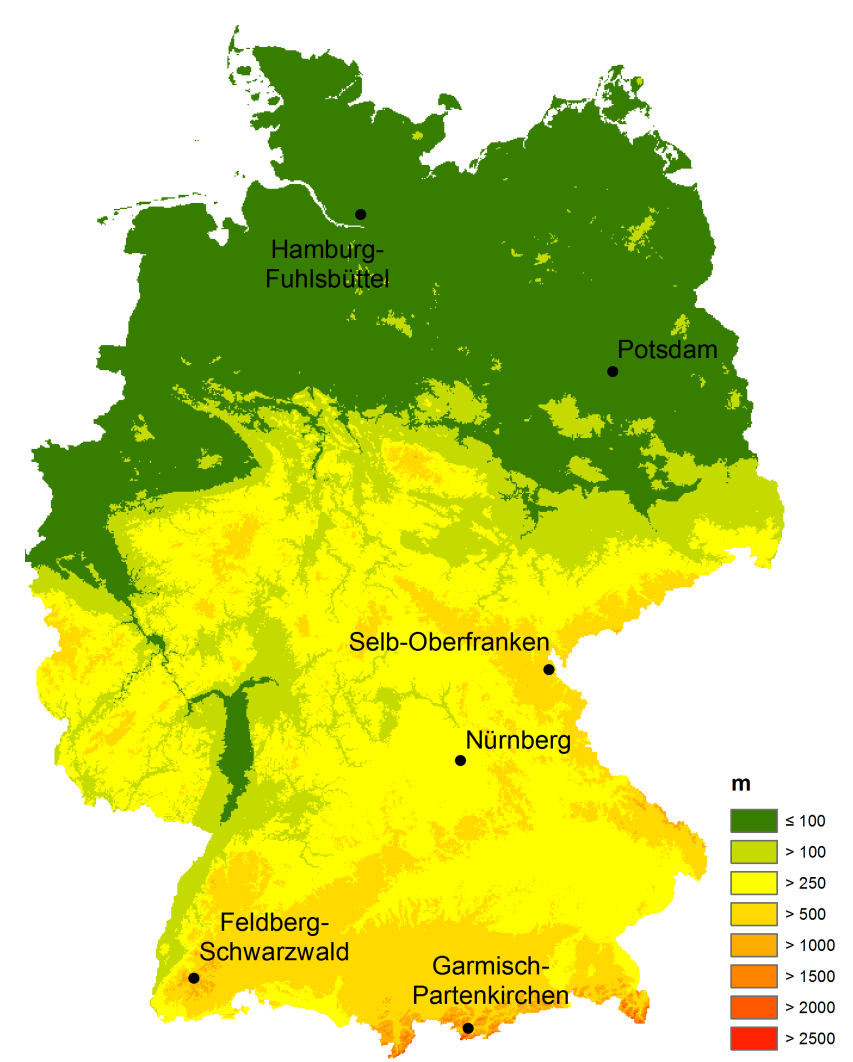

Figure 3. Topography of Germany with colour-coded height above sea level, and location of selected stations.

\subsection{Frequency distributions}

We compare the frequency distributions of daily-mean wind speed from the reanalyses with the distribution from the station observations, using the respective interpolated reanalysis grid cells containing the geographical location of the station. Daily-mean diagnostics were chosen to accommodate differ- ences in temporal sampling of the reanalyses ( 3 vs. $6 \mathrm{~h}$ for ERA-20C and ERA-Interim respectively).

For most station locations, the frequency distributions derived from the reanalyses match well with the one from the observations (e.g., Nuremberg, see Fig. 4). This might come as a surprise, given the rather coarse grid resolutions, and that the $10 \mathrm{~m}$ winds are expected to be strongly influenced by the local scale topography. Some stations show an offset in wind speed, due to the model height differing from the real topographic height, e.g., mountain stations like FeldbergSchwarzwald (Fig. 5). For some applications, fitness-forpurpose would therefore be improved by determining a more representative model height in cases of complex topography. Local influences of topography can result in pronounced differences in the frequency distributions. As an extreme example, the station Garmisch-Partenkirchen (Fig. 6) is shown, which is located in a valley for which the restricted representativity of the station cannot match the scales resolved in the reanalyses. Generally, only few histogram mismatches are found (and less for the higher resolved COSMO-REA6 reanalysis). An unexpected outcome was that some dubious station data could be identified: Fig. 7 shows an unusually large proportion of zero wind-speed values; it seems that these were in fact reported on occasions where no observations were performed. This illustrates the use of reanalysis data to support quality control for observed wind data.

Wind energy applications often require Weibull parameters, thus Weibull distributions with two parameters had been fitted to the frequency distributions:

$P(v)=\frac{k}{c}\left(\frac{v}{c}\right)^{k-1} e^{-\left(\frac{v}{c}\right) k}$,

where $v$ is the wind speed $(v \geq 0), k$ is the shape parameter $(k>0)$, and $c$ is the scale parameter of the distribution $(c>0)$. The Weibull parameters and error estimates are calculated with the maximum likelihood method implemented in the Cran R-project package fitdistrplus (Venables and Rip- 

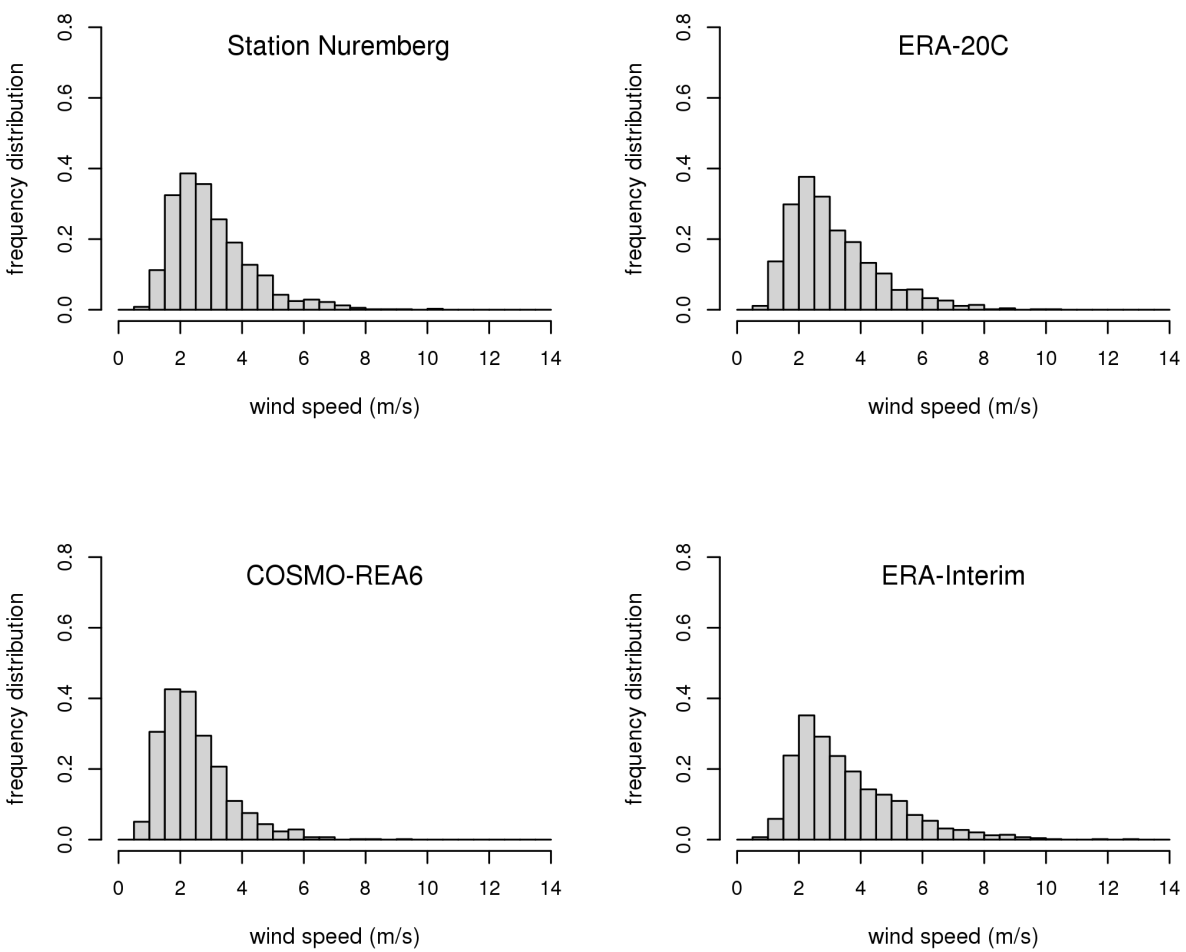

Figure 4. Frequency distribution of daily mean wind speeds in the period 2007 to 2010 for the station Nuremberg (top left) and matching grid cells of ERA-20C (top right), COSMO-REA6 (bottom left), and ERA-Interim wind fields (bottom right).
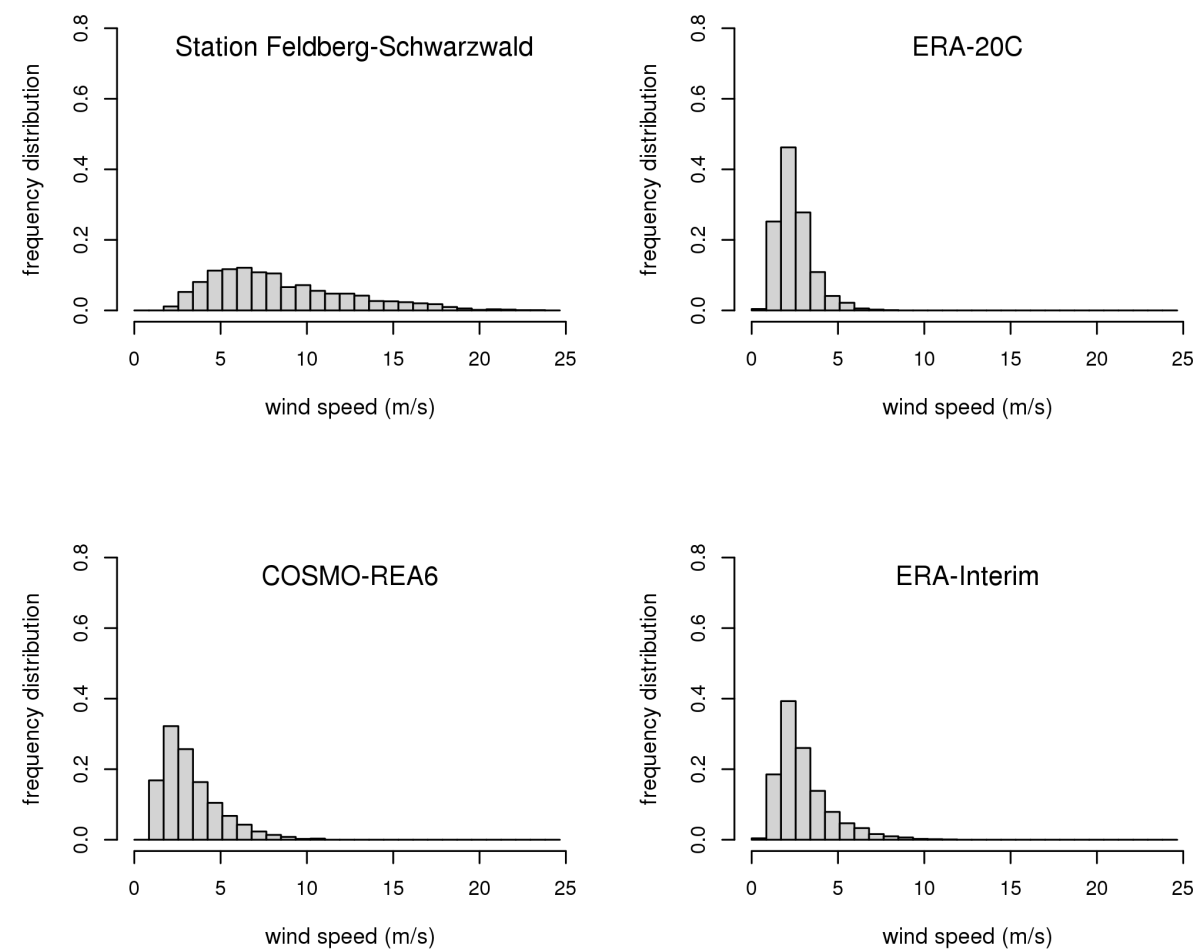

Figure 5. Frequency distribution of daily mean wind speeds in the period 2007 to 2010 for the station Feldberg-Schwarzwald (top left) and matching grid cells of ERA-20C (top right), COSMO-REA6 (bottom left), and ERA-Interim wind fields (bottom right). 

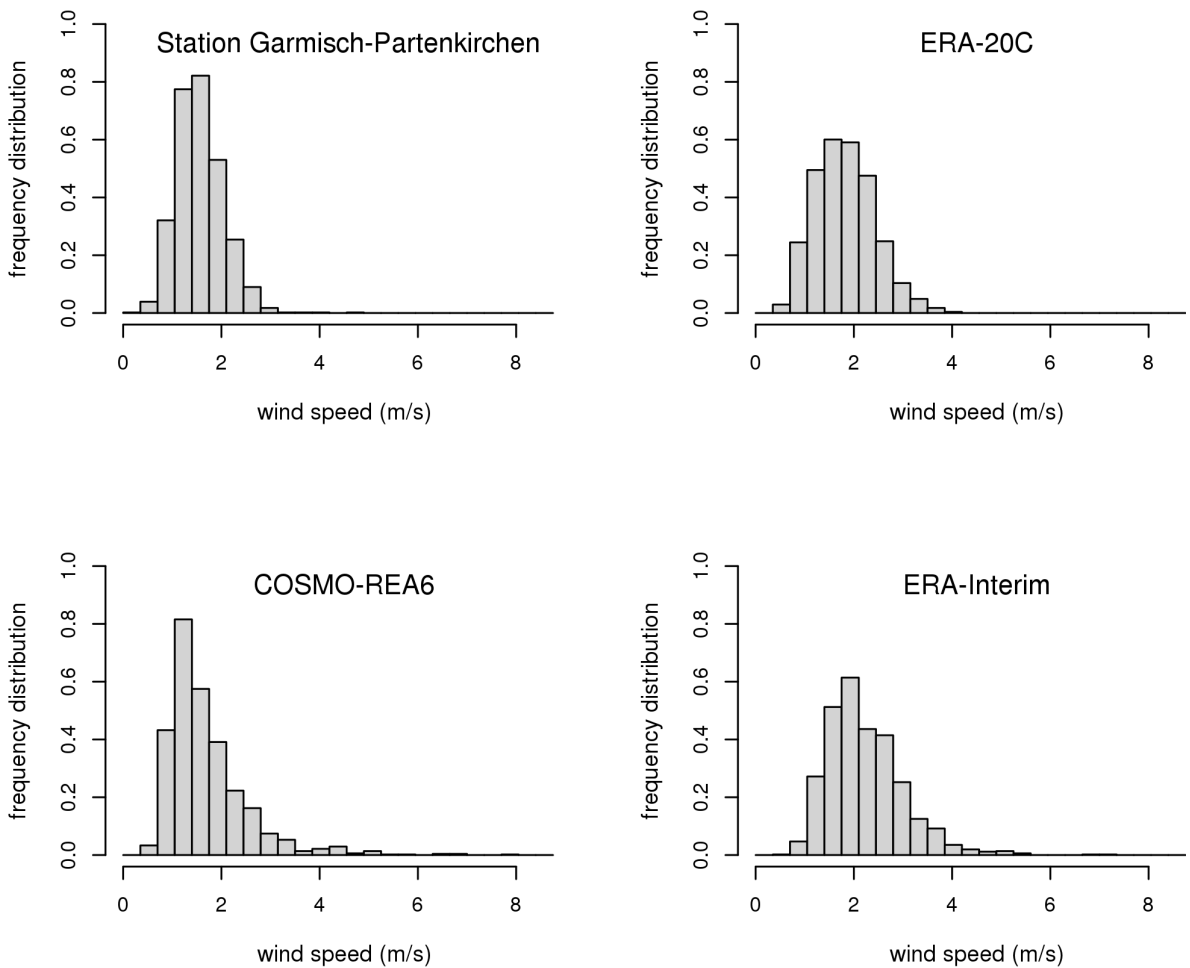

Figure 6. Frequency distribution of daily mean wind speeds in the period 2007 to 2010 for the example station Garmisch-Partenkirchen (top left) and matching grid cells of ERA-20C (top right), COSMO-REA6 (bottom left), and ERA-Interim wind fields (bottom right).
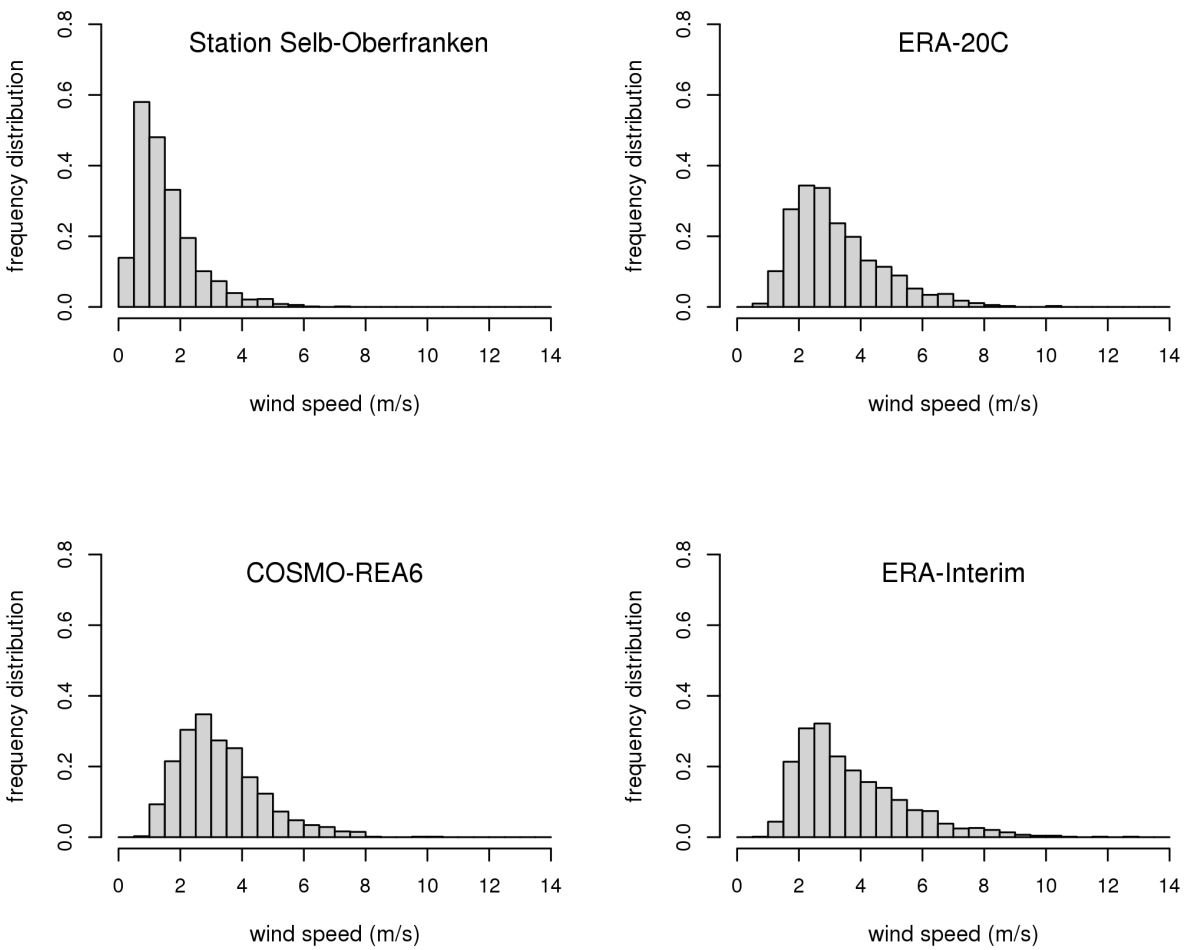

Figure 7. Frequency distribution of daily mean wind speeds in the period 2007 to 2010 for the station Selb-Oberfranken (top left) and matching grid cells of ERA-20C (top right), COSMO-REA6 (bottom left), and ERA-Interim wind fields (bottom right). 

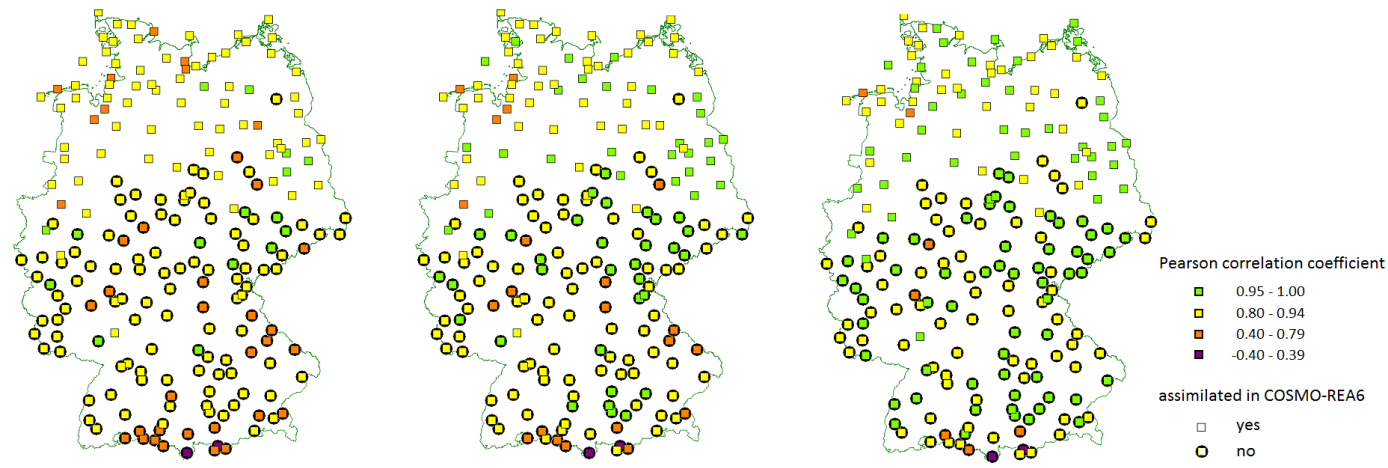

Figure 8. Pearson correlation coefficient of monthly mean wind speeds (calculated from daily wind speeds) between station observations and reanalyses: ERA-20C (left), ERA-Interim (middle), and COSMO-REA6 (right). Stations not assimilated in COSMO-REA6 are highlighted with grey circles.
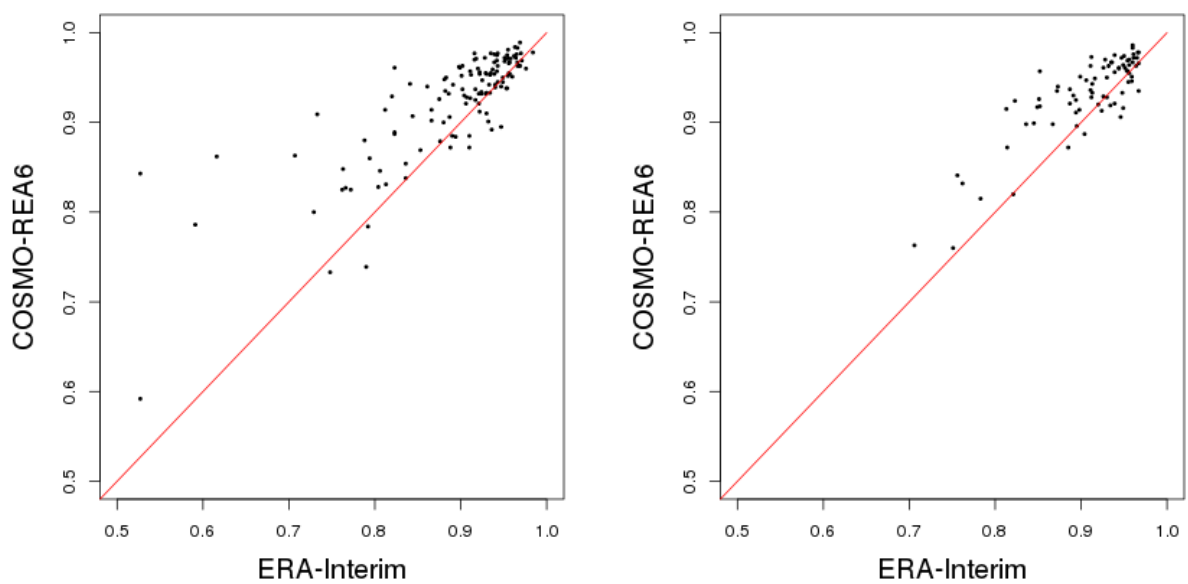

Figure 9. Scatterplots of Pearson correlation coefficients for stations that are not assimilated in COSMO-REA6 (left) and stations that are assimilated (right). Correlations are calculated between monthly mean wind speeds of station observations and COSMO-REA6 ( $y$ axis) and compared to correlations between station observations and ERA-Interim ( $x$ axis), respectively. Three of the total 210 stations are outliers (correlation below 0.5) and are not shown.

ley, 2010; Delignette-Muller et al., 2014). The Weibull parameters for selected stations are compared in Tables 1 and 2, with the dependence on station altitude (listed in Table 3) clearly prominent. For Hamburg-Fuhlsbüttel, the Weibull parameters $k_{\mathrm{S}}$ (shape) and $c_{\mathrm{S}}$ (scale) of the station observations match well with the ones from reanalyses, also for Potsdam and Nuremberg. Mountain stations like FeldbergSchwarzwald have significantly different $c$ (scale) parameters. Here a more representative height would be needed to be determined for each reanalysis. The situations in GarmischPartenkirchen and Selb-Oberfranken are different: The suspect histogram of the station data from Selb-Oberfranken (Fig. 7) causes a deviation of $k_{\mathrm{s}}$ (shape) and $c_{\mathrm{s}}$ (scale) due to issues with the missing values of the station recordings. For stations in complex topography, we expect significant differences in Weibull parameters due to the difference of real topography and model topography and the coarse reanalysis resolution. A close match of Weibull parameters (derived from stations and from reanalyses) could still be due to a favourable match of height above ground and above model ground. Thus we need to examine the correlation coefficients to judge whether reanalysis winds and station observations are in accordance. For instance, the Weibull parameters of the station Garmisch-Partenkirchen are not close, but still comparable to the ones from reanalysis (see Tables 1 and 2), but there is no correlation found between the time series of monthly means (see Table 3) which can be explained by its location in a valley.

\subsection{Correlation of reanalysis data with monthly station data}

The correlation of monthly wind speed from the ERA-20C, ERA-Interim, and COSMO-REA6 reanalyses with the 210 stations over Germany were calculated with the Pearson correlation for the period 2007 to 2010. In case of ERA-20C, 
Table 1. Weibull parameters $k$ (shape) derived from selected station daily mean wind observations ( $k_{\mathrm{S}}$ ), and from ERA-20C, ERA-Interim, and COSMO-REA6 interpolated grid cells matching the station locations, together with their $1 \sigma$ standard deviations (SD).

\begin{tabular}{lcccc}
\hline & $\begin{array}{c}k_{\mathrm{S}} \\
(\mathrm{SD})\end{array}$ & $\begin{array}{c}k_{-} \text {ERA-20C } \\
(\mathrm{SD})\end{array}$ & $\begin{array}{c}k_{-} \text {ERA-Interim } \\
(\mathrm{SD})\end{array}$ & $\begin{array}{c}k_{-} \text {COSMO-REA6 } \\
(\mathrm{SD})\end{array}$ \\
\hline Hamburg-Fuhlsbüttel & $2.65(0.05)$ & $2.61(0.05)$ & $2.56(0.05)$ & $2.62(0.05)$ \\
Potsdam & $2.89(0.05)$ & $2.56(0.05)$ & $2.48(0.05)$ & $2.73(0.05)$ \\
Nuremberg & $2.43(0.04)$ & $2.32(0.04)$ & $2.25(0.04)$ & $2.35(0.04)$ \\
Selb-Oberfranken & $1.68(0.03)$ & $2.36(0.04)$ & $2.26(0.04)$ & $2.56(0.05)$ \\
Garmisch-Partenkirchen & $3.40(0.06)$ & $3.26(0.06)$ & $2.94(0.05)$ & $2.17(0.04)$ \\
Feldberg-Schwarzwald & $2.26(0.05)$ & $2.55(0.05)$ & $2.07(0.04)$ & $2.07(0.04)$ \\
\hline
\end{tabular}

Table 2. Weibull parameters $c$ (scale) derived from selected station daily mean wind observations $\left(c_{\mathrm{S}}\right)$, and from ERA-20C, ERA-Interim, and COSMO-REA6 interpolated grid cells matching the station locations, together with their $1 \sigma$ standard deviations (SD).

\begin{tabular}{lcccc}
\hline & $\begin{array}{c}c_{\mathrm{S}} \\
(\mathrm{SD})\end{array}$ & $\begin{array}{c}c_{-} \text {ERA-20C } \\
(\mathrm{SD})\end{array}$ & $\begin{array}{c}c_{-} \text {ERA-Interim } \\
(\mathrm{SD})\end{array}$ & $\begin{array}{c}c_{-} \text {COSMO-REA6 } \\
(\mathrm{SD})\end{array}$ \\
\hline Hamburg-Fuhlsbüttel & $4.46(0.05)$ & $4.49(0.05)$ & $4.77(0.05)$ & $3.83(0.04)$ \\
Potsdam & $4.78(0.05)$ & $3.90(0.04)$ & $4.44(0.05)$ & $3.40(0.03)$ \\
Nuremberg & $3.39(0.04)$ & $3.50(0.04)$ & $3.99(0.05)$ & $2.79(0.03)$ \\
Selb-Oberfranken & $1.72(0.03)$ & $3.66(0.04)$ & $4.17(0.05)$ & $3.73(0.04)$ \\
Garmisch-Partenkirchen & $1.73(0.01)$ & $2.03(0.02)$ & $2.49(0.02)$ & $1.92(0.02)$ \\
Feldberg-Schwarzwald & $9.50(0.12)$ & $2.80(0.03)$ & $3.40(0.05)$ & $3.69(0.05)$ \\
\hline
\end{tabular}

$82 \%$ of stations show a correlation coefficient greater than or equal to 0.8 and $47 \%$ greater than or equal to 0.9 . For ERAInterim, these correlations are achieved at more stations (89 and $66 \%$, respectively), and yet more in COSMO-REA6 (96 and $80 \%$, respectively). The COSMO-REA6 reanalysis assimilates station observations below $100 \mathrm{~m}$ height; whether locations contribute assimilated observations or not can be distinguished in Figs. 8 and 9. In our case, 130 stations are not assimilated, i.e., are independent from COSMO-REA6. These independent stations show generally an improvement of correlation with COSMO-REA6 (Fig. 9). In Fig. 8 it can be seen that the regional reanalysis improves monthly correlations where it can be expected, namely in the areas with more complex topography (South of Germany, towards the Alps and Bayrischer Wald in the South-West). Three stations in complex terrain (Garmisch-Partenkirchen is one of them) have no correlation with the reanalyses and remain outside the scales of Fig. 9. Still, the correlations over time do hold (see Table 3) for several exposed mountain stations, like Feldberg-Schwarzwald.

Single stations only sometimes show statistically significant differences between the correlations with the three reanalyses, but the combined effect of the 210 stations becomes clear in Fig. 8, and especially in Fig. 9.

\subsection{Interannual variability related to NAO}

For many users, notably renewable energy users, the spatial characteristics and inter-annual variability of weather and cli- mate and its spatial extent are of special interest. The North Atlantic Oscillation (NAO) (Walker and Bliss, 1932; Hurell, 1995), is the main synoptic mode of atmospheric circulation and climate variability for Germany. Thus it is of interest, what the magnitude of the NAO-related effect is for the station data and to what extend the NAO-related effect is captured in the surface fields of the reanalysis over Germany.

For the recent years, the correlations of the stations and reanalysis fields are high. The question is, whether the correlation caused by NAO-related effects holds also for the past, keeping in mind the reanalysis systems might have longterm variability connected to changes of the observing system (Dee, 2005; Dee and Uppala, 2009). To describe the magnitude of the effect, we select seasonal averages for selected seasons corresponding to high, neutral, and low values of NAO index, and calculate the anomalies relative to the average of the period 2007 to 2010 . This is done with the interpolated ERA-20C near-surface fields. The station anomalies are calculated analogously, i.e., their reference is also derived from the station averages. In Fig. 10, we show examples for seasons from 2000 and 2002. The NAO-related anomalies show a west-east gradient (left), or a north-south gradient (middle and right) over Germany. The first panel (left) corresponds to a neutral NAO index autumn with higher than usual wind speeds over the western part and lower wind speeds in the East. With a negative NAO index, the average wind pattern is shifted southwards, leaving the North Sea area with lower wind speeds on average (middle panel). For the case of a positive NAO index, the wind pattern is shifted towards 
Table 3. Pearson correlation coefficient together with its $1 \sigma$-confidence interval, between mean monthly wind speeds from selected station observations and matching grid cells from interpolated ERA-20C, interpolated ERA-Interim, and COSMO-REA6. Note that for ERA-20C and ERA-Interim, all station observations are independent. For COSMO-REA6, station observations are assimilated (nudged) as indicated in the last column.

\begin{tabular}{|c|c|c|c|c|c|}
\hline Station & Altitude & $\begin{array}{l}\text { r_ERA-20C } \\
\text { (conf. int.) }\end{array}$ & $\begin{array}{l}\text { r_ERA-Interim } \\
\text { (conf. int.) }\end{array}$ & $\begin{array}{c}\text { r_COSMO-REA6 } \\
\text { (conf. int.) }\end{array}$ & nudged \\
\hline Hamburg-Fuhlsbüttel & 11 & $\begin{array}{c}0.93 \\
(0.90,0.94)\end{array}$ & $\begin{array}{c}0.96 \\
(0.95,0.97)\end{array}$ & $\begin{array}{c}0.98 \\
(0.97,0.98)\end{array}$ & yes \\
\hline Potsdam & 81 & $\begin{array}{c}0.94 \\
(0.92,0.96)\end{array}$ & $\begin{array}{c}0.96 \\
(0.95,0.97)\end{array}$ & $\begin{array}{c}0.98 \\
(0.98,0.99)\end{array}$ & yes \\
\hline Nuremberg & 314 & $\begin{array}{c}0.93 \\
(0.90,0.94)\end{array}$ & $\begin{array}{c}0.92 \\
(0.89,0.94)\end{array}$ & $\begin{array}{c}0.97 \\
(0.96,0.98)\end{array}$ & no \\
\hline Selb-Oberfranken & 535 & $\begin{array}{c}0.86 \\
(0.82,0.90)\end{array}$ & $\begin{array}{c}0.89 \\
(0.86,0.92)\end{array}$ & $\begin{array}{c}0.89 \\
(0.85,0.91)\end{array}$ & no \\
\hline Garmisch-Partenkirchen & 719 & $\begin{array}{c}-0.23 \\
(-0.36,-0.09)\end{array}$ & $\begin{array}{c}-0.11 \\
(-0.38,0.18)\end{array}$ & $\begin{array}{c}-0.04 \\
(-0.18,0.12)\end{array}$ & no \\
\hline Feldberg-Schwarzwald & 1490 & $\begin{array}{c}0.90 \\
(0.87,0.92)\end{array}$ & $\begin{array}{c}0.89 \\
(0.85,0.91)\end{array}$ & $\begin{array}{c}0.93 \\
(0.91,0.95)\end{array}$ & no \\
\hline
\end{tabular}
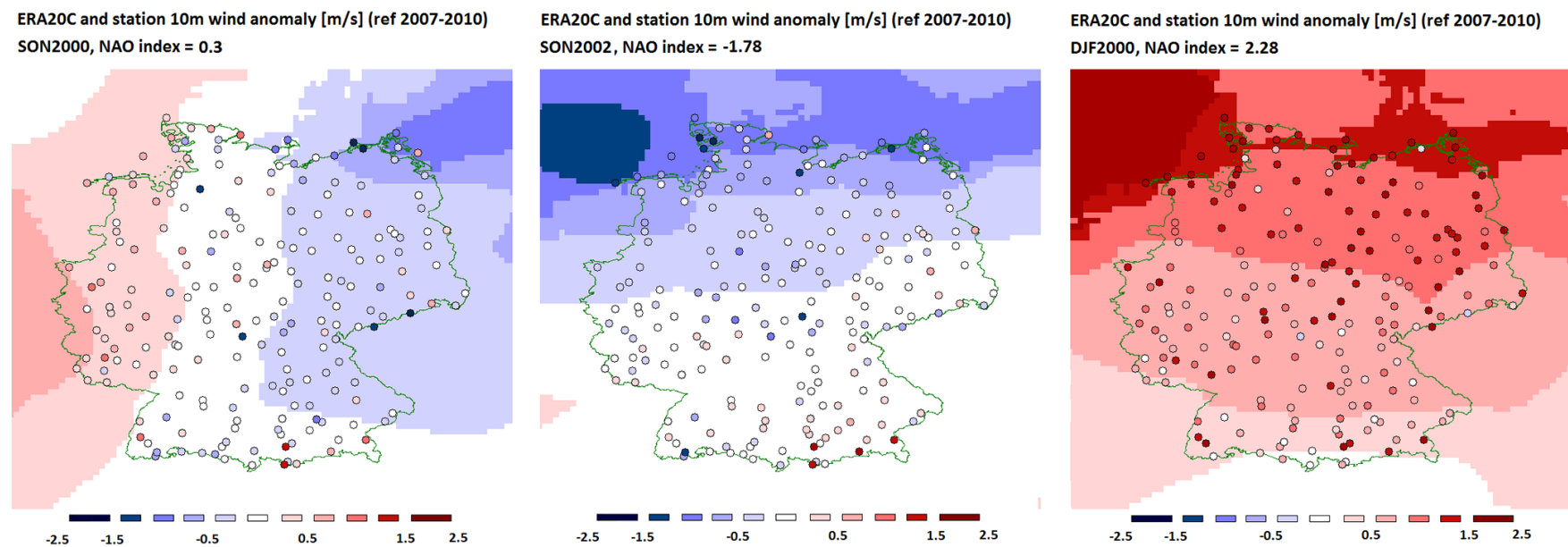

Figure 10. Seasonal anomalies of the ERA-20C $10 \mathrm{~m}$ wind speeds compared to the reference period 2007 to 2010 for September, October, November (SON) of 2000 at neutral NAO-index (left panel), SON2002 at negative NAO-index (middle), and December, January, February (DJF) 1999/2000 at positive NAO-index (right).

the North (left panel). Note that, allowing for some scatter among the stations, they generally match the spatial extent and the magnitude of the anomaly present in the ERA$20 \mathrm{C}$ fields. The examples picked here have months with a similar NAO-index, and a rather pronounced NAO anomaly. Of course, the inter-annual wind variability is dependent not only on the NAO strength, but also on details of the jet stream position, and the individual storm tracks, when moving to shorter time scales and selected station positions. Our conclusion here is that the inter-annual variability in the near surface winds captured in the reanalyses is consistent with the station time series, considering a time scale of several years. We can detect this common NAO-pattern (in both reanalysis and station data) in recent years. To extend our studies to longer time scales, we would have to separate the effect of instrumental changes at the stations from possible effects of NAO-related variability. For instance, Welker and Martius (2015) found a positive correlation between the NAO-index and occurrence of high wind speeds over Switzerland, deduced from the global 20CR reanalysis (Compo et al., 2011) on the inter-annual time scale. Welker and Martius (2015) found an increase of the correlation at the decadal time scale; and point to a change of strength of this correlation over time due to an eastward shift of the NAO pattern.

\subsection{Comparing feedback statistics}

The opportunities to compare reanalyses against stable time series of fully-independent observations covering a long time-period are limited. Fortunately, the reanalysis process 


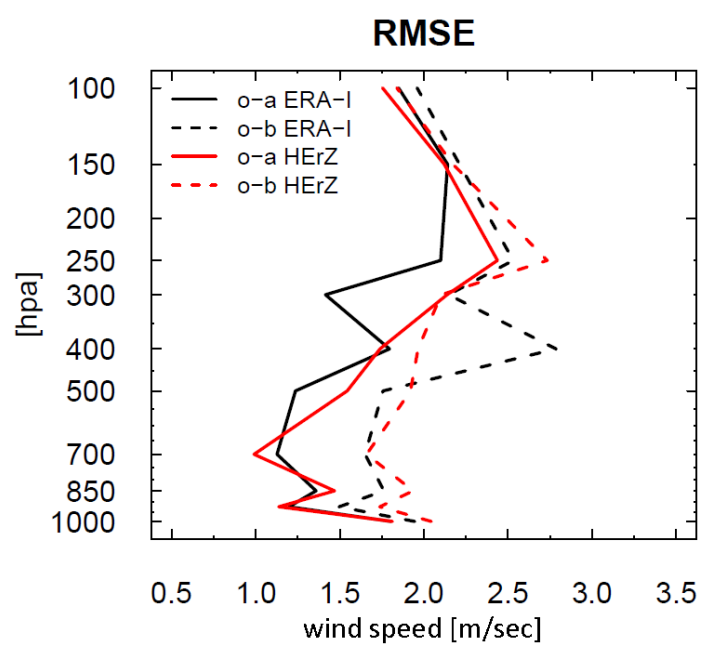

Figure 11. Root mean square errors of analysis departures (o-a, solid line) and background departures (o-b, dashed line) for Lindenberg radiosonde observations of wind speed at standard pressure levels, in January 2011: feedback statistics for the ERA-Interim (black) and COSMO-REA6 (red).

provides opportunities to use the assimilated observations in a quasi-independent manner, by comparing these observations against the free forecasts (or background fields) which are started from the preceding (re-)analysis window. These so-called feedback statistics are in fact routinely produced by the data assimilation system, and relate assimilated observations, free forecasts (i.e., background fields), analysis increments, and analysis fields to each other. They yield valuable additional information, e.g., estimates of the analysis error or diagnostics on systematic changes in increments which, if traced to biases in observations or model (or both), indicate deficiencies in the system. Favourable statistics may show that the frequency distribution and time series of observed and reanalysed parameters are matching. Thus, it is potentially of high practical value for the user to take into account the results of feedback statistics.

As a demonstration of concept, here we analyse the differences between observations (o), background (b), and (re-)analysis (a) of wind speed for a global (ERA-Interim) and the COSMO-REA6 regional reanalysis, for the Lindenberg radiosondes launched at $06 \mathrm{Z}$ (see Fig. 11). Care must be taken to make the differences arising from different reanalysis systems as comparable as possible. In particular, the uncertainties of the background fields from the reanalysis systems should be made as similar as possible. These uncertainties depend on the initial condition uncertainty and the growth of this uncertainty with forecast lead time. The forecast lead times of both systems should be comparable. In our example, COSMO background fields valid at $06 \mathrm{Z}$ are taken from forecasts initialized at $0 \mathrm{Z}$ and propagated for a lead time of $6 \mathrm{~h}$. The most comparable ERA-Interim background fields are from forecasts initialized at $3 \mathrm{Z}$ and prop- agated for a lead time of $3 \mathrm{~h}$. In addition, the sounding data that have influenced the initial conditions for the background forecasts in both systems are comparable. At leading order, the regional and global reanalyses both match the sounding observations to the same extent, for the statistical sample investigated here. The match is not uniform, for example ERA-Interim o-b exhibits large values around $400 \mathrm{hPa}$ while COSMO o-b exceeds ERA-Interim o-b between 1000 and $700 \mathrm{hPa}$. While the limited sample shown here does not permit such discrepancies to be definitively traced to specific system deficiencies, this example highlights a more general issue: namely, that relatively few users have the tools and skills to identify such discrepancies, or to make informed assessments of any consequent impacts in their particular application, and hence lack clarity on whether a dataset is fit for their specific purpose. We believe that these are important issues that warrant attention in the context of current efforts to develop climate services.

To draw conclusion on the performance of the different systems, a comparison of observations to background (o-b) is easier to interpret than observations to analysis (o-a), because the background can be regarded, in first approximation (in the absence of time-correlated errors), as rather independent from the observations. From Fig. 11 we can see that the background of ERA-Interim and COSMO-REA6 are similar, but differ to up to $25 \%$. Both analyses are drawn closer to the observations, which shows the effect of the data assimilation for this example. Comparing the resulting analyses with each other is harder, because the analysis depends on the observations to a degree that varies between the different assimilation systems. For more conclusions, longer periods of feedback statistics with comparable forecast lead times should be analysed, which were not available at the time of writing.

\section{Summary and conclusions}

Here we inter-compared the frequency distributions, Weibull parameters and monthly to inter-annual variability of regional and global reanalysis near surface wind fields of the recent years (2007-2010). We illustrated three approaches, namely direct comparison (with independent station measurements), thematic comparison (the magnitude and spatial extend of NAO-related mean wind speed anomalies) and internal metrics (feedback statistics).

The $2 \sigma$ confidence intervals of the Weibull parameters derived from the reanalysis wind fields overlap the ones derived from the stations in most cases for the Weibull shape parameter $(k)$, whereas the Weibull scale parameters $(c)$ differ more. With respect to correlations, generally the ERA$20 \mathrm{C}$ fits the station data well, ERA-Interim fits better, and the regional COSMO-REA6 reanalysis is closest to the station data. This is valid for the daily, monthly, and seasonal scale, for the period investigated here (2007 to 2010). It has to be kept in mind that the station observations situated be- 
low $100 \mathrm{~m}$ a.s.1. are assimilated within COSMO-REA6. The increased correlation with COSMO-REA6 holds true regardless whether or not a station contributes observations that are assimilated in COSMO-REA6. Noticeable improvement for COSMO-REA6 correlations are found across Germany, for instance at stations in Southern Germany, closer to the Alps (not assimilated in COSMO-REA6), and at the coastline (assimilated in COSMO-REA6).

As expected from the fact that the regional COSMOREA6 reanalysis is driven by the global ERA-Interim reanalysis via boundary condition, the feedback statistics exhibit a similar fit to the Lindenberg radio soundings for both reanalysis systems for our example month of January 2011.

We demonstrated that although local and regional effects can be expected to determine the variability in wind fields measured at the stations ( $10 \mathrm{~m}$ over ground), the frequency distributions of mean wind speeds match quite well with the ones of the reanalysis fields for which such effects are at the sub-grid scale. The correlation of ERA-20C, ERA-Interim and COSMO-REA6 monthly means with station observations is high ( $>0.8$ ) for the majority of the German stations. Thus we conclude that the monthly and seasonal anomalies recorded at these stations can be understood as representative for a wider spatial area, comparable to the resolution of the reanalyses, at least for the recent years. Due to the shortness of period, we cannot make such a statement concerning inter-annual variability, though the NAO-related anomalies indicate there is also coherence at the inter-annual scale.

The correlation holds for ERA-20C, even though fewer observations are assimilated than in ERA-Interim and the spatial resolution is significantly reduced. The correlation with COSMO-REA6 reanalysis is highest, because of several, and possibly combined, reasons: the higher resolution of the model, the regional data assimilation (nudging), and possibly also the higher temporal resolution of the output. It should be kept in mind that COSMO-REA6 is forced every $3 \mathrm{~h}$ by ERA-Interim, and we compare aggregated daily means from hourly COSMO-REA6 output with daily means from 6-hourly ERA-Interim output. While skill is inherited from ERA-Interim via boundary conditions, we get the additional benefit from COSMO-REA6, possibly also from the temporal resolution. Particular the stations with low correlations show a strong improvement, pointing to the expected difference in the reanalysis performance, namely that the smaller scales which are resolved with COSMO-REA6 are of importance for the monthly mean near surface wind speeds, i.e., hinting to that a simple scaling of global reanalysis would not give the same information (on the daily to monthly time scale).

Further analysis would be needed to identify under which circumstances the differences are most pronounced, and to what extent the low-frequency information from global reanalyses is represented or improved with regional reanalyses for regional-scale parameters.
Author contributions. The ideas and methodologies were developed by Andrea Kaiser-Weiss, Frank Kaspar, David Tan, Paul Poli and Hilppa Gregow during the CORE-CLIMAX project. Analyses in the manuscript were conducted by Andrea Kaiser-Weiss, Frank Kaspar, Vera Heene, Michael Borsche and Andre Obregon. Andrea Kaiser-Weiss prepared the manuscript with contribution from all co-authors.

Acknowledgements. Andre Obregon and Vera Heene were supported through the CORE-CLIMAX (grant no. 313085 within the EU Seventh Framework Programme). Michael Borsche is supported by the UERRA project (grant no. 607193 within the EU Seventh Framework Programme). We thank Christoph Bollmeyer and Liselotte Bach from University of Bonn for the provision of the COSMO-REA6 feedback files. We thank Karsten Friedrich (DWD) for his help with the figures. We would like to acknowledge helpful discussions with Hermann Mächel (DWD). We thank our two reviewers for their constructive criticism which improved the manuscript.

Edited by: E. Bazile

Reviewed by: T. Landelius and one anonymous referee

\section{References}

Bichet, A., Wild, M., Folini, D., and Schär, C.: Causes for decadal variations of wind speed over land: Sensitivity studies with a global climate model. Geophys. Res. Lett., 39, L11701, doi:10.1029/2012GL051685, 2012.

Bollmeyer, C., Keller, J. D., Ohlwein, C., Wahl, S., Crewell, S., Friederichs, P., Hense, A., Keune, J., Kneifel, S., Pscheidt, I., Redl, S., and Steinke, S.: Towards a high-resolution regional reanalysis for the European CORDEX domain, Q. J. Roy. Meteorol. Soc., 141, 1-15, doi:10.1002/qj.2486, 2014.

Bosilovich, M. G., Kennedy, J., Dee, D., Allan, R., and O’Neill, A.: On the Reprocessing and Reanalysis of Observations for Climate. Climate Science for Serving Society: Research, Modelling and Prediction Priorities, edited by: Asrar, G. and Hurrell, J. W., Springer Netherlands, 51-71, 2013.

Compo, G. P., Whitaker, J. S., Sardeshmukh, P. D., Matsui, N., Allan, R. J., Yin, X., Gleason, B. E., Vose, R. S., Rutledge, G., Bessemoulin, P., Brönnimann, S., Brunet, M., Crouthamel, R. I., Grant, A. N., Groisman, P. Y., Jones, P. D., Kruk, M. C., Kruger, A. C., Marshall, G. J., Maugeri, M., Mok, H. Y., Nordli, Ø., Ross, T. F., Trigo, R. M., Wang, X. L., Woodruff, S. D., and Worley, S. J.: The Twentieth Century Reanalysis Project. Q. J. Roy. Meteorol. Soc., 137, 1-28, doi:10.1002/qj.776, 2011.

Dee, D. P.: Bias and data assimilation, Q. J. Roy. Meteorol. Soc., 131, 3323-3343, doi:10.1256/qj.05.137, 2005.

Dee, D. P. and Uppala, S.: Variational bias correction of satellite radiance data in the ERA-Interim reanalysis, Q. J. Roy. Meteorol. Soc., 135, 1830-1841, doi:10.1002/qj.493, 2009.

Dee, D. P., Uppala, S. M., Simmons, A. J., Berrisford, P., Poli, P., Kobayashi, S., Andrae, U., Balmaseda, M. A., Balsamo, G., Bauer, P., Bechtold, P., Beljaars, A. C. M., van de Berg, L., Bidlot, J., Bormann, N., Delsol, C., Dragani, R., Fuentes, M., Geer, A. J., Haimberger, L., Healy, S. B., Hersbach, H., Hólm, E. V., 
Isaksen, L., Kållberg, P., Köhler, M., Matricardi, M., McNally, A. P., Monge-Sanz, B. M., Morcrette, J.-J., Park, B.-K., Peubey, C., de Rosnay, P., Tavolato, C., Thépaut, J.-N., and Vitart, F.: The ERA-Interim reanalysis: configuration and performance of the data assimilation system, Q. J. Roy. Meteorol. Soc., 137, 553597, doi:10.1002/qj.828, 2011.

Dee, D. P., Balmaseda, M., Balsamo, G., Engelen, R., Simmons, A. J., and Thepaut, J.-N.: Towards a consistent reanalysis of the climate system, B. Am. Meteorol. Soc., 95, 1235-1248, doi:10.1175/BAMS-D-13-00043.1, 2014.

Delignette-Muller, M., Pouillot, R., Denis, J., and Dutang, C.:_tdistrplus: Help to Fit of a Parametric Distribution to Non-Censored or Censored Data, R package version 1.0-2, available at: http: //cran.r-project.org (last access: 1 April 2015), 2014.

Gerth, W. P. and Christoffer, J.: Windkarten von Deutschland, Meteorolog. Zeitschrift, N.F., 3, 67-77, 1994.

Gregow, H., Poli, P., Mäkelä, H. M., Jylhä, K., Kaiser-Weiss, A. K., Obregon, A., Tan, D. G. H., Kekki, S., and Kaspar, F.: User awareness concerning feedback data and input observations used in reanalysis systems, Adv. Sci. Res., 12, 63-67, doi:10.5194/asr12-63-2015, 2015.

Hartmann, D. L., Klein Tank, A. M. G., Rusticucci, M., Alexander, L. V., Brönnimann, S., Charabi, Y., Dentener, F. J., Dlugokencky, E. J., Easterling, D. R., Kaplan, A., Soden, B. J., Thorne, P. W., Wild, M., and Zhai, P. M.: Observations: Atmosphere and Surface, in: Climate Change 2013: The Physical Science Basis. Contribution of Working Group I to the Fifth Assessment Report of the Intergovernmental Panel on Climate Change. Cambridge University Press, Cambridge, United Kingdom and New York, NY, USA, 2013.

Hurrell, J. W.: Decadal trends in the North Atlantic oscillation: regional temperature and precipitation, Science, 269, 676-697, 1995.

Jones, P. D., Jónsson, T., and Wheeler, D.: Extension to the North Atlantic Oscillation using early instrumental pressure observations from Gibraltar and South-West Iceland, Int. J. Climatol., 17, 1433-1450, 1997.

Kaspar, F., Müller-Westermeier, G., Penda, E., Mächel, H., Zimmermann, K., Kaiser-Weiss, A., and Deutschländer, T.: Monitoring of climate change in Germany - data, products and services of Germany's National Climate Data Centre, Adv. Sci. Res., 10, 99-106, doi:10.5194/asr-10-99-2013, 2013.
McVicar, T. R., Van Niel, T. G., Li, L. T., Roderick, M. L., Rayner, D. P., Ricciardulli, L., and Donohue R. J., Wind speed climatology and trends for Australia, 1975-2006: Capturing the stilling phenomenon and comparison with nearsurface reanalysis output, Geophys. Res. Lett., 35, L20403, doi:10.1029/2008GL035627, 2008.

McVicar, T. R., Roderick, M. L., Donohue, R. J., Li, L. T., Van Niel, T. G., Thomas, A., Grieser, J., Jhajharia, D., Himri, Y., Mahowald, N. M., Mescherskaya, A. V., Kruger, A. C., Rehman, S., and Dinpashoh, Y.: Global review and synthesis of trends in observed terrestrial near-surface wind speeds: Implications for evaporation, J. Hydrol., 416-417, 182-205, 2012.

Poli, P., Hersbach, H., Tan, D., Dee, D., Thépaut, J.-N., Simmons, A., Peubey, C., Laloyaux, P., Komori, T., Berrisford, P., Dragani, R., Trémolet, Y., Holm, E., Bonavita, M., Isaksen, L., and Fisher, M.: The data assimilation system and initial performance evaluation of the ECMWF pilot reanalysis of the 20th-century assimilating surface observations only (ERA-20C), ERA report series No. 14, European Centre for Medium-Range Weather Forecasts, Reading, England, 2013.

Smits, A., Klein-Tank, A. M. G., and Können, G. P.: Trends in storminess over the Netherlands, 1962-2002, Int. J. Climatol., 25, 1331-1344, doi:10.1002/joc.1195, 2005.

Vautard, R., Cattiaux, J., Yiou, P., Thépaut, J.-N., and Ciais, P.: Northern Hemisphere atmospheric stilling partly attributed to an increase in surface roughness, Nature GeoScience, 3, 756-761, 2010.

Venables, W. N. and Ripley, B. D.: Modern Applied Statistics with S, 4th Edn., Springer-Verlag, 2010.

Walker, G. T. and Bliss, E. W.: World Weather V, Mem. R. Meteorol. Soc., 4, 53-84, 1932.

Welker, C. and Martius, O.: Large-scale atmospheric flow conditions and sea surface temperatures associated with hazardous winds in Switzerland, Clim. Dynam., 44, 1857-1869, doi:10.1007/s00382-014-2404-1, 2015.

Wever, N.: Quantifying trends in surface roughness and the effect on surface wind speed observations, J. Geophys. Res., 117, D11104, doi:10.1029/2011JD017118, 2012. 